\title{
Disparities in surgical resection of early-stage non-small cell lung cancer
}

\author{
Abdul R. Jazieh, MD, MPH ${ }^{a}$ \\ Mohammad J. Kyasa, MD ${ }^{b}$ \\ Goplan Sethuraman, $\mathrm{PhD}^{\mathrm{a}}$ \\ John Howington, MD
}

From the University of Cincinnati, Cincinnati, Ohio, ${ }^{\mathrm{a}}$ and the University of Arkansas for Medical Sciences, Little Rock, Ark. ${ }^{\text {b }}$

Received for publication Dec 11, 2001; revisions requested Dec 11, 2001; revisions received Dec 19, 2001; accepted for publication Jan 2, 2002.

Address for reprints: Abdul Rahman Jazieh, MD, MPH, The Barrett Center for Cancer, Hematology/Oncology, ML 0501, 234 Goodman Ave, Cincinnati, OH 45267-0501 (E-mail: jaziehar@uc.edu).

J Thorac Cardiovasc Surg 2002;123:1173-6 Copyright $\odot 2002$ by The American Association for Thoracic Surgery

$0022-5223 / 2002 \$ 35.00+0 \quad \mathbf{1 2 / 1 / 1 2 2 5 3 8}$ doi: $10.1067 / \mathrm{mtc} .2002 .122538$
Objectives: The aim of our study was to identify the factors that determined whether a patient underwent surgery and its impact on patient outcome.

Methods: A retrospective evaluation of the records of all patients diagnosed with resectable stages I and II non-small cell lung cancer between 1990 and 1998 at the University of Arkansas and Veterans Administration Hospitals were included in the study. Demographic, clinical, pathologic, and outcome data were captured. Analysis was conducted to identify prognostic factors as well as factors leading to surgical treatment disparities.

Results: A total of 551 patients were included; 490 (89\%) were men, 480 (87\%) were white, and $315(57 \%)$ were aged $>65$ years. Median follow-up of these patients was 24 months (1-109 months). Surgery was performed on 455 patients (82.6\%); 26 patients received nonsurgical treatment including chemotherapy, radiation therapy, or both, and 70 patients did not receive any type of treatment. A univariate analysis revealed that age, race, sex, and forced expiratory volume in the first second were significantly different between the surgery and no surgery groups. However, a multivariate analysis showed that age, forced expiratory volume in 1 second, and hemoglobin were significantly different between both groups. The median overall survival was 45.5 months (1-109 months) for the surgically treated patients compared with 12.0 months $(1-86$ months) for those who did not undergo surgery $(P<.0001)$.

Conclusion: Elderly patients with early-stage non-small cell lung cancer are less likely to undergo a potentially curative surgical resection. Racial and sex disparities may be due to other comorbidities.

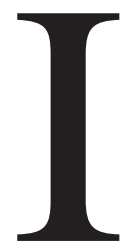

$\mathrm{t}$ is estimated that 169,500 Americans will be given a diagnosis of lung cancer in 2001, and 157,400 persons will succumb to this disease. ${ }^{1}$ A 5-year survival of less than $15 \%$, combined with the high incidence, makes lung cancer the leading cause of cancer deaths in the United States. Different therapeutic modalities are used in the management of lung cancer, depending on the tumor stage and the patient's clinical status.

Surgical resection remains the preferred therapeutic modality for early stages of non-small cell lung cancer (NSCLC), especially stages I and II, yet one third to one half of these patients die within 5 years of diagnosis. ${ }^{2-5}$ Furthermore, many patients with early stages of NSCLC do not undergo tumor resection because of comorbidi- 
TABLE 1. Patient characteristics $(\mathrm{n}=551)$

\begin{tabular}{lr}
\hline Characteristics & No. (\%) \\
\hline Age (y) & \\
$\leq 65$ & $236(42.8)$ \\
$>65$ & $315(57.2)$ \\
Sex & \\
$\quad$ Male & $490(88.9)$ \\
$\quad$ Female & $61(11.1)$ \\
Race & \\
White & $480(87.1)$ \\
African American & $70(12.7)$ \\
Disease stage & \\
I & $457(82.9)$ \\
II & $94(17.1)$ \\
Surgical resection & \\
Yes & $455(82.6)$ \\
No & $96(17.4)$
\end{tabular}

TABLE 2. Comparison between patients who underwent surgical resection for NSCLC and those who did not undergo surgical resection

\begin{tabular}{|c|c|c|c|}
\hline Variable & $\begin{array}{l}\text { Surgical } \\
\text { resection }\end{array}$ & $\begin{array}{c}\text { No } \\
\text { surgical } \\
\text { resection }\end{array}$ & $P$ value \\
\hline \multicolumn{4}{|l|}{ Age (y) } \\
\hline$\leq 65$ & 205 & 31 & .02 \\
\hline$>65$ & 250 & 65 & \\
\hline \multicolumn{4}{|l|}{ Race } \\
\hline White & 405 & 75 & .01 \\
\hline African American & 49 & 21 & \\
\hline \multicolumn{4}{|l|}{ Sex } \\
\hline Male & 411 & 79 & .02 \\
\hline Female & 44 & 17 & \\
\hline \multicolumn{4}{|l|}{ Disease stage } \\
\hline I & 380 & 77 & .4 \\
\hline II & 75 & 19 & \\
\hline Median $\mathrm{FEV}_{1}(\mathrm{~L})$ & 2 & 1.2 & $<.0001$ \\
\hline Median hemoglobin level ( $\mathrm{g} / \mathrm{dL})$ & 13.8 & 13.5 & .09 \\
\hline
\end{tabular}

ties or patient or physician preference. Patients who are not treated with surgical intervention usually have worse outcomes. Therefore the reasons for disparities in the treatment modality should always be revisited, especially in light of recent advances in therapeutic interventions.

This article reports the disparities in undergoing surgical resection for stage I and II NSCLC and the differences between patients treated with surgical resection and those who did not have an operation.

\section{Patients and Methods}

\section{Patient Selection}

This study included all patients with stage I and II NSCLC between 1991 and 1998. All of these patients were treated at the

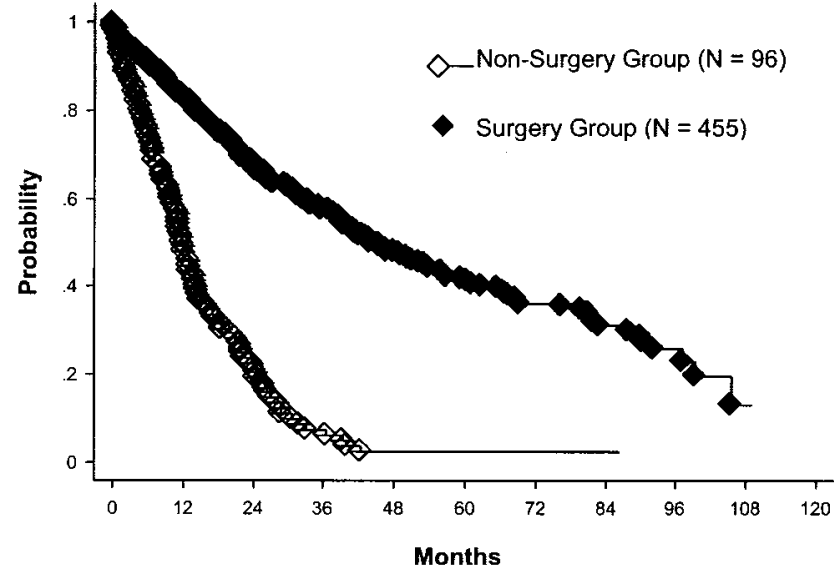

Figure 1. Kaplan-Meier cumulative survival plot for overall survival.

University of Arkansas Hospital and the Veterans Administration Hospital.

\section{Study Design}

Data were collected by means of a retrospective review of medical records, tumor registry records, pathology reports and slides, and radiology reports. The data collected included patient characteristics, such as age, race, sex, date of diagnosis, tumor site, type of treatment, type of relapse or recurrence, and cause of death. Other tumor data collected included histologic subtype and grade, tumor margins, tumor size, number of lymph nodes sampled, number of positive lymph nodes, and pathologic TNM staging for patients who underwent an operation. For patients who did not undergo an operation, the clinical staging was used. Clinical staging included computed tomographic scanning of the chest in all patients and computed tomographic scanning of the brain, liver, and adrenals and bone scanning when clinically indicated. Hemoglobin level, albumin level, and forced expiratory volume in 1 second $\left(\mathrm{FEV}_{1}\right)$ at the time of diagnosis were also included.

\section{Statistical Analysis}

Patient demographics and medical characteristics were summarized with descriptive statistics (ie, percentages, medians, and ranges). Overall survival estimates for each group were obtained by using the Kaplan-Meier (product-limit) methodology, and survival distributions were compared by using log-rank tests. Demographic, clinical, laboratory, and pathologic factors were compared between the 2 groups. Factors significantly associated with the outcome were included in a Cox proportional hazards model. All analyses were performed with SAS/STAT software, version 7 (SAS Institute Inc, Cary, NC). A comparison between the characteristics of the group of patients undergoing surgical resection and the group of patients not undergoing resection was conducted by using a logistic regression model to determine significant differences. Significant variables were entered into a multivariate model analysis to identify the interaction between these variables. 
TABLE 3. Results of logistic regression modeling for patients undergoing surgical resection versus those not undergoing resection

\begin{tabular}{|c|c|c|c|}
\hline Variable & $\begin{array}{c}\text { Parameter } \\
\text { estimate (SE) }\end{array}$ & $\begin{array}{l}\text { Odds ratio } \\
\text { (95\% Cl) }\end{array}$ & $\chi^{2}(P$ value $)$ \\
\hline Age, y $(>65$ vs $\leq 65)$ & $0.66(0.26)$ & $1.93(1.16-3.20)$ & $6.41(.01)$ \\
\hline Hemoglobin level, g/dL (>10 vs $\leq 10)$ & $1.49(0.27)$ & $4.4(2.59-7.52)$ & $29.93(<.0001)$ \\
\hline $\mathrm{FEV}_{1}, \mathrm{~L}(>1$ vs $\leq 1)$ & $1.2(0.26)$ & $3.33(1.98-5.59)$ & $20.71(<.0001)$ \\
\hline
\end{tabular}

\section{Results}

Five hundred fifty-one patients were included in this study. The median age of these patients was 67 years (range, 39-83 years), $89 \%$ were men (which was a result of the large proportion of VA patients), and $87 \%$ were white. Median follow-up was 24 months (range, 1-109 months). Patient characteristics are listed in Table 1. Four hundred fifty-five $(82.6 \%)$ patients underwent surgical resection of their tumors, and $96(17.4 \%)$ patients did not undergo surgical resection. The reasons for not undergoing an operation were poor pulmonary function test results $(\mathrm{n}=70)$, debilitating medical problems $(n=15)$, and patient refusal $(n=11)$. Of the group not undergoing an operation, 70 patients received no treatment for their cancer. The remaining 26 patients had various treatments, including chemotherapy in 12 patients, radiation therapy in 2 patients, and combined chemotherapy and radiation in 13 patients. The comparison between the group undergoing an operation and the group not undergoing an operation revealed that older patients ( $>65$ years) were less likely to undergo surgical intervention compared with younger patients $(79 \%$ vs $87 \%, P<.02)$. In addition, women were less likely to receive surgical treatment than men $(72 \%$ vs $84 \%, P<.02$; Table 2$)$.

Analysis of the race data revealed that African American subjects were less likely to undergo surgical intervention when compared with white subjects $(70 \%$ vs $84 \%, P<$ .001). Analysis combining sex and race revealed that African American men were less likely to undergo an operation (70\% vs $86 \%, P<.004)$, but there was no difference between African American women and white women. Patients who underwent surgical intervention had higher $\mathrm{FEV}_{1}$ values than the group of patients who did not ( 2 vs $1.2 \mathrm{~L}$, $P<.0001)$. There were no differences between the groups undergoing and not undergoing surgical treatment regarding stage and hemoglobin level. However, when a multivariate analysis including these variables was performed, only age, hemoglobin level, and $\mathrm{FEV}_{1}$ were significant factors (Table $3)$.

The median survival of patients who underwent an operation was 45.5 months (range, 1-109 months) compared with 12 months (range, 1-86 months) for the group of patients who did not $(P<.0001$, Figure 1).

A univariate analysis of race, age, sex, stage, hemoglobin level, and $\mathrm{FEV}_{1}$ revealed that age, stage, hemoglobin level,
TABLE 4. Univariate analysis of different variables and overall survival

\begin{tabular}{lcc}
\hline Variable & Overall survival & $P$ value \\
\hline Median age $(\mathrm{y})$ & & \\
$\quad \leq 65$ & 46.2 & $<.0001$ \\
$\quad>65$ & 26.0 & \\
Sex & & \\
$\quad$ Male & 33.2 & .98 \\
$\quad$ Female & 30.6 & \\
Race & & \\
$\quad$ White & 33.3 & .5 \\
$\quad$ African American & 31.9 & \\
Disease stage & & \\
$\quad$ I & 38.0 & .0001 \\
$\quad$ II & 16.2 & \\
Surgical resection & & \\
$\quad$ Yes & 45.5 & \\
$\quad$ No & 12.0 & \\
Hemoglobin level (g/dL) & & \\
$\quad>10$ & 39.3 & $<.0001$ \\
$\quad \leq 10$ & 20.2 & \\
FEV $_{1}$ (L) & & \\
$\quad>1$ & 37.8 & $<.0001$ \\
$\quad \leq 1$ & 16.3 & \\
\hline
\end{tabular}

and $\mathrm{FEV}_{1}$ had a significant correlation with survival (Table 4).

A multivariate analysis confirmed all the latter factors to be independent predictors for overall survival (Table 5).

\section{Discussion}

Surgical resection is the gold standard treatment for stage I and II NSCLC. Patients who do not undergo surgical resection have a worse outcome. The results of this study are consistent with this known fact. Although the majority of patients underwent an operation, $17.4 \%$ did not, which is in line with reported resection rates of $5 \%$ to $32 \% .^{2,6}$

Elderly patients are less likely to receive potentially curative surgical treatment for different cancers, ${ }^{7}$ which might be due to comorbidities and many other socioeconomic factors. Age disparity was apparent in our study, with fewer operations performed on older patients, leading to worse outcomes in these patients. Although age should not be a reason for offering less than standard therapy to patients, aggressive invasive therapy might not be possible in 
TABLE 5. Results of Cox proportional hazards model for overall survival

\begin{tabular}{lccc}
\hline Variable & $\begin{array}{c}\text { Parameter } \\
\text { estimate (SE) }\end{array}$ & $\begin{array}{c}\text { Hazard ratio } \\
(\mathbf{9 5 \%} \text { CI) }\end{array}$ & $\begin{array}{c}\text { Wald } \chi^{2}(\boldsymbol{P} \\
\text { value })\end{array}$ \\
\hline Surgical resection & $-1.4(0.13)$ & $0.25(0.19-0.32)$ & $113.36(<.0001)$ \\
Age & $0.49(0.12)$ & $1.63(1.3-2.05)$ & $17.48(<.0001)$ \\
Disease stage & $0.53(0.14)$ & $1.69(1.29-2.23)$ & $14.02(.0002)$ \\
Hemoglobin level & $-0.76(0.13)$ & $0.47(0.36-0.6)$ & $33.64(<.0001)$ \\
FEV & $-0.3(0.13)$ & $0.74(0.57-0.95)$ & $5.52(.02)$ \\
\hline
\end{tabular}

many elderly patients. ${ }^{8}$ The resection rate in our older group compares favorably with that in the reported literature. The evolution of video-assisted surgery and lung volume-reducing surgery might increase the number of elderly patients undergoing surgical resection.

Racial disparities in the management of cancers have been reported. For example, African Americans were reported to have less operations for colorectal cancers, even after adjusting for age, comorbidities, and tumor stage. ${ }^{9}$ The reasons for racial disparities might be due in part to patient preference or difficulty in communicating and not primarily because of racial discrimination. ${ }^{10-12}$ However, reports of racial disparities in the management of early-stage NSCLC focused on elderly patients (Medicare data) and did not include other important demographic and clinical factors. ${ }^{6,13}$ In this study the apparent racial disparity in the univariate analysis was not an independent predictor of treatment when adjusted for age, pulmonary function test results, and hemoglobin levels. This means, at least in this study, that there are other reasons for racial disparity. Furthermore, overall survival was similar for both races, which also further confirmed the lack of significant racial discrimination.

Our results did not show any sex-based difference in the management of these patients and no difference in survival between men and women.

As expected, patients with poor pulmonary function test results were less likely to undergo an operation. The use of volume-reduction surgery and video-assisted surgery also might increase the number of patients with limited pulmonary function undergoing surgical treatment.

Anemia was reported to be an independent prognostic factor for patients with stage I and II NSCLC who underwent surgical resection. ${ }^{14}$ In this study patients with anemia also seemed to have less chance of undergoing an operation and shorter survival.

Finally, disparity in the management of cancer is complicated by various demographic, socioeconomic, and clin- ical factors. Physicians are encouraged to look at the patterns of their practice to minimize any possible remediable disparity.

We thank Mohammed Hussain, MD, and Pat Coke, CRA, for their help in data collection and Ms Nancy Crossen for her help in manuscript preparation.

\section{References}

1. Greenlee RT, Hill-Harmon MB, Murray T. Cancer Statistics, 2001. CA Cancer J Clin. 2001;51:15-36.

2. Flehinger BJ, Kimmel M, Melamed MR. The effect of surgical treatment on survival from early lung cancer: Implication for screening. Chest. 1992;101:1013-8.

3. Read RC, Shaefer RC, North N, Walls R. Diameter, cell type, and survival in stage I primary non-small cell lung cancer. Arch Surg. 1988;123:446-9.

4. Martini N, Burt ME, Bains MS. Survival after resection of stage I and II non-small cell lung cancer. Ann Thorac Surg. 1992;54:460-5.

5. Pairolero PC, William DE, Bergstralh EJ, Piehler JM, Bernatz PE, Payne WS. Postsurgical stage I bronchogenic carcinoma: Morbid implications of recurrent disease. Ann Thorac Surg. 1984;59:412-5.

6. Bach PB, Cramer LD, Warren JL, Begg CB. Racial differences in the treatment of early stage lung cancer. N Engl J Med. 1999;341:1198205 .

7. Samet J, Hunt WC, Key C, Humble CG, Goodwin JS. Choice of cancer therapy varies with age of patient. JAMA. 1986;255:3385-90.

8. Kemeny MM, Busch-Devereaux E, Merriam LT, O'Hea BJ. Cancer surgery in the elderly. Hematol Oncol Clin North Am. 2000;14:16992.

9. Cooper GS, Yuan Z, Landefeld CS, Rimm AA. Surgery for colorectal cancer: race-related differences in rates and survival among Medicare beneficiaries. Am J Public Health. 1996;86:582-6.

10. Ayanian JZ, Cleary PD, Weissman JS, Epstein Am. The effect of patients' preferences on racial differences in access to renal transplantation. N Engl J Med. 1999;341:1661-9.

11. Epstein AM, Ayanian JZ. Racial disparities in medical care. $N$ Engl J Med. 2001;344:1471-2.

12. Chen J, Rathore SS, Radford MJ, Wang Y, Krumholz HM. Racial differences in the use of cardiac catheterization after acute myocardial infarction. $N$ Engl J Med. 2001;344:1443-9.

13. Greenwald HP, Polissar NL, Borgatt EF, McCorkle R, Goodman G. Social factors, treatment, and survival in early stage non-small cell lung cancer. Am J Public Health. 1998;88:1681-4.

14. Jazieh AR, Hussain M, Howington JA, Spencer HJ, Husain M, Grismer JT, et al. Prognostic factors in patients with surgically resected stages I and II non-small cell lung cancer. Ann Thorac Surg. 2000; 70:1168-71. 